This is a pre-publication version of the paper published in Human Studies (2014), 37 (2), 279-286. DOI 10.1007/s10746-014-9310-8.

\title{
Reflecting on the ethics and politics of collecting interactional data: Implications for training and practice
}

FOR: SPECIAL ISSUE, ETHICAL ISSUES IN COLLECTING INTERACTIONAL DATA,

ED. ISABELLA PAOLETTI.

Dr Susan A. Speer

Senior Lecturer in Psychology

School of Psychological Sciences (Psychology Division)

Coupland Building 1

The University of Manchester

Oxford Road

Manchester M13 9PL

UK

Email: susan.speer@manchester.ac.uk

Word count: 3,818 including references.

Key words:

Ethics, conversation analysis, ethnomethodology, interaction, research methods, reflexivity. 


\section{Reflecting on the ethics and politics of collecting interactional data: Implications for training and practice}

\section{Introduction}

This special issue brings together researchers from psychology and linguistics who apply the ethnomethodologically informed analytic technique of conversation analysis (henceforth CA) to examine a range of ethical issues as they emerge in transcribed recordings of interactions collected as part of routine research encounters. The data authors analyse are diverse, including naturalistic audio and video recordings of members' everyday and professional practices (Mondada, in press), an ethnography of a gynaecology unit in a public hospital in Italy (Fatigante and Orletti in press), focus group interviews on domestic family life (Alby and Fatigante, in press), and semi-public meetings, recorded as part of an ethnography of ageing, poverty and social exclusion (Paoletti, in press b). Noting that 'ethical issues in research have seldom been the focus of ethnomethodological studies' (Paoletti in press a: 7, see also Mondada: 5), the primary aim of this special issue is to 'open a debate on ethical issues in collecting interactional data within an ethnomethodological perspective, stimulating theoretical reflection and empirical research into the social dimension of data collection' (Paoletti, in press a: 8). In this short commentary I will pick out what I take to be some of the commonalities and differences across the papers, before reflecting on the implications they raise for ethical research practice and research methodology more broadly.

The papers in this special issue share four features in common:

\section{(i) Respecify ethical issues as analytic topics}

According to Mondada, much of the literature on research ethics adopts an etic point of view, offering standardised regulations and guidelines for the conduct of research as set out in the codes of professional bodies, and remedies for the difficulties researchers may encounter. As 
Mondada notes, 'these forms of advice concern mainly how researchers should proceed rather than how they actually act on the field' (p.4). By contrast, an alternative, 'emic' approach adopted by the authors in this special issue, formulates ethical concerns endogenously, from the perspective of the participants who are part of the setting under study.

Rather than treating ethical issues as methodological problems that need to be solved by the researcher before data collection and analysis can begin, an ethnomethodological framework, following Garfinkel (1967, 1991), respecifies scientific questions, including ethical issues, as members' problems (Mondada in press: 3), treating them as a topic for scientific inquiry in their own right (Mondada in press: 3 and 30). From this perspective, ethical matters are studied as practical issues that are raised, oriented to, and managed locally, by members, in situ, in the course of their participation in the social activities of their research participation (in press: 6). This is a 'symmetrical' approach in which neither the researchers' nor participants' contributions to an interaction are exempt from analytic scrutiny: 'Ethics in action' is achieved by both researchers and participants in the course of their recorded interactions (in press: 30), and ethical issues or problems, including informed consent and anonymisation of data, are examined as they are oriented to and unfold in actual research situations, as practical researchers' and participants' concerns. Hence, this ethnomethodological framework entails a focus on precisely those ethical problems that researchers tend not to disclose, and those moments of research interactions that are typically hidden from analytic scrutiny, exploring the way members themselves work creatively to find solutions to these problems (in press: 3 ).

Each paper considers a different ethical concern as it unfolds interactionally, grounding it in an analysis of the empirical details of actual, everyday research practice, and 'the live context in which the research takes place' (Fatigante and Orletti, in press: 3). 
Mondada (in press) explores how members define for themselves in an ongoing fashion what they take to be the limits of their consent to the recording of their interactions, by considering the issue of anonymisation of data as a members' concern. She shows how members orient to certain of their activities as delicate, and hence requiring anonymisation, and the practical and skilled solutions/practices or 'ethnomethods' (in press: 31 ) they employ in order to actively achieve anonymisation and disguise their identities. Fatigante and Orletti consider a possible mismatch between the ethical concerns that guide the 'ideal' procedure for gaining consent at the start of the research process, as exemplified in consecutive iterations of their consent form, and the ethical concerns that are made relevant by doctors, nurses and patients during the 'actual' unfolding of the research process. Alby and Fatigante explore the interviewer's different strategies of identity management in achieving an understanding of, and preserving, the interviewees' standpoints, and promoting an ethical research relationship. Finally, adopting an overtly political position of 'social responsibility' toward her research participants, Paoletti examines (i) the interactional dimensions of ethical dilemmas associated with the negotiation of consent in meetings in semi-public settings, and (ii) the ethical dilemma of whether to censure a participant with a view to protecting their anonymity, or give them a critical voice that would expose organisational inefficiencies at their place of work.

\section{(ii) Adopt a reflexive approach to ethical issues}

Second, the authors share an understanding of the importance of adopting a reflexive approach to research ethics. There are at least two kinds of reflexivity (Lynch 2000). The first involves the researcher adopting a reflexive perspective on data collection. For example, researchers working within a qualitative, anthropological and ethnographic framework typically reflect in an autobiographical fashion on the real world ethical problems that they 
face in the course of conducting research with human participants, and the methodological solutions they adopted. This approach treats the researcher as an (ideally) relatively neutral conduit for the collection of research data, and has identified 'possible discrepancies between the conception and the purposes of the fieldworker and those of the participants - especially when these are children, minority groups, or marginal populations' (Mondada, in press: 5). The second, ethnomethodological type of reflexivity considers the reflexivity of members, including the researcher. From this perspective, researchers are seen, not as neutral conduits for the collection of data, but as part of the social worlds they inhabit. Mondada advocates the second kind of reflexivity, while others adopt perspectives that sit somewhere between the two. For example, Paoletti argues that 'researchers need to be aware and responsible for the impact they have in the setting they study (in press a: 12-13, in press b), and of the 'inescapably social nature of data collection' (in press b: 22). Similarly. Alby and Fatigante 'promote the development of a reflexive awareness and sensitivity to one's work as interviewer and solicit the exploration of one's own talk and of the subtleties of interactions as an object of inquiry in its own' (in press: 23).

\section{(iii) Highlight a discrepancy between ethics procedures and practices}

Third, by subjecting methodological practices to detailed analytic scrutiny, each paper, to varying degrees, exposes a discrepancy between ethical procedures, as set out in methods textbooks and the codes of various professional bodies and associations, and practices as they play out in actual research situations (Fatigante and Orletti in press: 2; see also Gilbert \& Mulkay, 1984). For example, Mondada justifies her focus on members' practices of anonymization by highlighting a divergence between the 'normative-prescriptive' approaches to anonymization contained in the a priori guidelines of ethics bodies that offer 'lists of items to be anonymized' (in press: 7), and anonymization as carried out in situ from the 
perspectives of the participants engaged in ordinary research activities. In their paper on gynaecology encounters, Fatigante and Orletti highlight the difficulties associated with adjusting the idealised informed consent procedure which aims to provide participants with 'enough information.... to express free will in choosing whether or not to participate' (in press: 15) and which set out rules for the protection of privacy, to the rather more complex research practice in live contexts, where participants' (i.e., doctors, nurses and patients participating in the study) make their own, online choices about, and have methods for indexing, which of their talk and actions should be open to public scrutiny (in press: 28). Alby and Fatigante (in press: 20ff) highlight a contrast between the 'neutral' (impartial, institutional, impersonal, formal) and 'embodied' (partisan, personalised, empathic, reciprocal), stances adopted by an interviewer, and their implications for an 'ethical listenership' that respects and preserves the participant's perspective. Finally, noting that 'ethics in research cannot be reduced to "rule-following", divorced from moral and ethical reasoning', Paoletti (in press a : 7) highlights a divergence between the formal requirements of research ethics committees, which she describes as 'insufficient for confronting the complexities of actual ethical problems emerging from research activities' (in press a : 8), and the problems associated with using informed consent forms in certain research settings, such as semi-public meetings (in press b: 10). For Paoletti, to use a consent form at the time of seeking consent from strangers congregating at a public event 'was impracticable and... would have seriously jeopardized the participants' activity' (in press b: 16).

\section{(iv) Consider implications for ethical research practice}

Fourth, consistent with an ethnomethodological framework, Mondada treats methodological problems as 'topics for inquiry', rather than things to be solved, and hence her main focus is the analysis of members' (rather than analysts') ongoing solutions to the ethical dilemmas 
they encounter (in press: 30). However, she does offer a 'practical hint' (in press: 12) or 'reflexive suggestion' (in press: 30) 'by showing how analyses of members' orientations can aliment a specific, ad hoc, transcription and treatment of the data, respectful of their situated and emergent concerns' (in press: 31 ). The rest of the authors in the special issue share a more politicised conceptualisation of relational ethics that assumes 'responsibility in relation to the social reality under study' (Paoletti, in press a: 2, see also Alby and Fatigante, in press: 23). They suggest a range of solutions to the ethical problems they identify with a view to making research more ethical and producing 'more fair and effective research relationships' (Paoletti intro: 13).

Fatigante and Orletti suggest that (i) participants should be offered 'the opportunity to discuss informed consent,.... voice their concerns and interpretations, and revise - if they feel the need - their authorization even soon after the visit' in order to properly respect the patients' autonomy and right to 'full awareness of what they consented to' (in press: 32); and (ii) that ethical procedures might be better communicated to participants by 'open[ing] up an interlocutory context in which the research plan and its antecedents can be openly disclosed by the researcher, rather than embedded and disguised as self-evident information in the consent letter' (in press 32). Finally, Alby and Fatigante suggest that analyses should consider 'the interactional effects that the interviewer's stance taking can produce' (in press: 23). For them ethical research needs to take account of the 'different strategies of identity management and different standpoints as resources' to understand the world from the participants' points of view' (in press: 1).

Paoletti extends her recommendations further, suggesting that systematic reflection by researchers 'on the social and interactional dimension of how ethical decisions were taken during actual research activities' (in press: 22) could feed into the development of 'more realistic and useful' ethics guidelines (in press b: 22). 
By exposing methodological practices that are typically hidden to detailed analytic scrutiny, the papers in this special issue make an important contribution to the growing tradition of ethnomethodologically-based studies of research methods in practice (e.g., Drew, Raymond \& Weinberg, 2006; Maynard et al., 2002, 2010), and to social science research methodology more broadly. As Paoletti suggests, this new focus represents an 'empirical turn in the approach to ethical questions in conducting social research' (in press a: 8).

I am in broad agreement with the ethnomethodological framework adopted by the authors in this special issue. In my own work I have used conversation analysis to explore two issues related to ethics in action:

(i) In the first strand of my work I turned the methodological problem of 'reactivity' on its head by exploring participants' orientations to the presence and relevance of recording devices (Speer and Hutchby 2003a, 2003b; Hammersley, 2003). This work challenged the view of many researchers that awareness of recording and 'tape-affected speech' would render overtly-recorded (and hence ethical) data 'unnatural' (Speer 2002a, 2002b; see also Stokoe, 2009).

(ii) In the second strand of my work I explored how informed consent is gained from research participants (Speer and Stokoe, 2012). In an analysis of consent-gaining examples similar to those discussed by Paoletti (in press b: 11-17), I explored how 'requests' to consent in research played out across different institutional settings. For example, our findings raised questions about the extent to which participants "agreed to participate without [interactional] pressure or coercion" (General Medical Council, 2010: 8): Consent-gaining sequences tended to constrain opting out of research, because consent-gaining turns were tilted grammatically 
in favour of continued participation, making opting-out a dispreferred response (Pomerantz, 1984).

These papers share a similar perspective on ethics to the contributions in this special issue, revealing a mismatch between what ethics guidelines specify about the reactivity of overt recording and consent-gaining 'in theory' and what actually happens 'in practice'.

Collectively they challenge researchers to subject their research-based interactions to analytic scrutiny. Indeed, I am of the view that, as recent work in 'applied CA' shows (see Antaki, 2011), interaction research can make a significant contribution to practice. Although that contribution has traditionally equated to recommendations in respect of institutional practices not directly related to the conduct of research, this special issue, and my own work reported above, are indicative of a move toward using studies of interaction to make recommendations for the theory and practise of research methods in general, and research ethics in particular. However, if anything, the papers in this special issue downplay their potential contribution in this respect.

For example, one point that is made implicitly across the papers, but which might be argued more forcefully and explicitly, is that ethics guidelines of all kinds are based on a misunderstanding of how interaction works, and an assumption that it is both possible and desirable to translate written guidelines unproblematically, and pristinely, into spoken interaction (Speer and Stokoe, 2012). The mismatch between theory and practice these studies highlight is not to suggest that we should use our findings to identify examples of unethical research, or, in the case of the second of strand of my work referred to above, that researchers should attempt to standardize ethics scripts in a bid to 'engineer out' interactional preference from consent-gaining sequences. Rather, it could be argued that the guidelines themselves are problematic because they do not engage with the interactional contingencies 
and preference structures associated with, for example, the everyday actions of 'requesting' and 'declining' informed consent; actions that may be especially problematic in research settings where there is an asymmetry of institutional roles (Gill et al., 2001, Speer and Stokoe, 2012).

As others have shown, even where a researcher has standardization of a research script or consent form as their explicit goal, it does not tend to occur in practice, where interactional contingencies comes into play (e.g., Maynard et al., 2002; Maynard \& Schaeffer, 2006; Schegloff, 2002, Speer and Stokoe, 2012; Stokoe, 2013). Research interactions are not exempt from talk's everyday procedures, and are no less interactional by virtue of their status as research: We cannot stop people from talking using normative conversational procedures. However, the papers in this special issue point to the importance of seeking to understand how interaction works before constructing guidelines or codes for actions that are to be delivered interactively (Speer and Stokoe, 2012). As Sacks argued some time ago, 'from close looking at the world you can find things that we couldn't, by imagination, assert were there' (1992: 2: 420).

Findings reported here suggest that there may always be a tension between maximizing consent to participate in research and ensuring that decisions to participate or not, and to continue to participate or not, are fully informed (Wade et al., 2009: 2025). Ultimately, ethical research practice comes not from the development of increasingly stringent research guidelines and codes, but from understanding the possible effects of our interactions on participants, and of participants' interactions on us.

This brings me to a second way in which the papers in this special issue may downplay their potential contribution to the theory and practice of research, which relates to the value of a reflexive approach grounded in interactional data, for researcher training (Lomax \& Casey, 1998; Speer, 2002c). Such an approach would entail those parties who may 
be responsible for collecting data from recipients discussing their research interactions, reflecting on what works well, what works less well, and for whom. The goal would not be to identify some codable, decontextualised practices that are intrinsically 'better' for research ethics than others. Rather, by exploring patterns in recordings of real life research interactions showing researchers and recording parties doing different things with different outcomes, researchers would be able to discuss what constitutes ethical practice in a particular study, on the basis of what real researchers and participants in specific contexts actually do (see also Speer 2013). Consistent with the growing tradition of work in applied conversation analysis (see chapters in Antaki 2011), such an approach would entail researchers adopting an empirically grounded, data driven operationalisation of ethical research practice that can accommodate the interactional nuances at play in real life research settings, and the variable, functional specificity of interaction across the full range of research domains. Only in this way might researchers be able to adequately consider, in light of the apparent functional purpose of the interaction, 'do the ends (e.g. obtaining important data) justify the means (e.g., adopting practices that imply interactional constraint or coercion)?' Researchers may benefit from looking at the kinds of real-life research interactions displayed here to discuss precisely this question.

\section{Acknowledgement}

I would like to thank Elizabeth Stokoe and Isabella Paoletti for their helpful comments on an earlier draft.

\section{References}

Alby, F. and Fatigante, M. (in press) Preserving the respondent's standpoint in a research interview: Different strategies of 'doing' the interviewerHuman Studies. 
Antaki, C. (Ed.), Applied conversation analysis: Changing institutional practices. Basingstoke: Palgrave Macmillan.

Drew, P., Raymond, G., \& Weinberg, D. (Eds.) (2006). Talk and interaction in social research methods. London: Sage.

Fatigante, M. and Orletti, F. (in press) From principles to practice: Information giving in written consent forms and in participants' talk recorded in a hospital setting. Human Studies.

Garfinkel, H. (1967). Studies in Ethnomethodology. Englewood Cliffs, N.J.: Prentice-Hall.

Garfinkel, H. (1991). Respecification: Evidence for locally produced, naturally accountable phenomena of order*, logic, reason, meaning, method, etc. in and as of the essential haecceity of immortal ordinary society (I) — an announcement of studies. In G. Button (Ed.), Ethnomethodology and the Human Sciences (pp. 10-19). Cambridge: Cambridge University Press.

General Medical Council (2010). Good practice in research and consent to research. Online document, retrieved 27 February 2012 from: http://www.gmcuk.org/static/documents/content/Research_guidance_FINAL.pdf

Gilbert, G.N., \& Mulkay, M. (1984). Opening Pandora's Box: A sociological analysis of scientists' discourse. Cambridge: Cambridge University Press.

Gill, V. T., Halkowski, T., \& Roberts, F. (2001). Accomplishing a request without making one: A single case analysis of a primary care visit. Text, 21, 55-81.

Hammersley, M. (2003). Analytics are no substitute for methodology: A response to Speer and Hutchby. Sociology, 37, 339-52.

Lomax, H., N. \& Casey, N. (1998). 'Recording social life: Reflexivity and video methodology. Sociological Research Online, 3. Online document, retrieved 27 February 2012 from: http://www.soc.surrey.ac.uk/socresonline/3/2/1.html 
Lynch, M. (2000). Against reflexivity as an academic virtue and source of privileged knowledge. Theory, Culture \& Society, 17(3), 26-54.

Maynard, D. W.; Freese, J. \& Schaeffer, N. C. (2010). Calling for participation: Requests, blocking moves, and rational (inter)action in survey introductions. American Sociological Review, 75, 791-814.

Maynard, D. W., Houtkoop-Steenstra, H., Schaeffer, N. C. \& van der Zouwen, J. (Eds.) (2002). Standardization and tacit knowledge. Interaction and practice in the survey interview. New York: John Wiley.

Maynard, D. W., \& N. C. Schaeffer (2006). Standardization-in-interaction: The survey interview. In P. Drew, G. Raymond, \& D. Weinberg (Eds.), Talk and interaction in social research methods (pp. 9-27). London. Sage.

Mondada, L. (in press) Ethics in action: Anonymization as a partiiocpant's concern and a participant's practice. Human Studies.

Paoletti, I. (in press, a) Introduction to the special issue: Ethical issues in collecting interactional data. Human Studies.

Paoletti, I. (in press) Ethics and the social dimension of research activities. Human Studies.

Pomerantz, A. (1984). Agreeing and disagreeing with assessments: Some features of preferred/dispreferred turn shapes. In J. M. Atkinson, \& J. Heritage (Eds.), Structures of social action: Studies in conversation analysis (pp. 57-101). Cambridge: Cambridge University Press.

Sacks, Harvey (1992) Lectures on conversation. 2 vols. Edited by Gail Jefferson with introductions by Emanuel A. Schegloff. Oxford: Basil Blackwell.

Schegloff, E. A. (2002). Survey interviews as talk-in-interaction. In D. W. Maynard, H. Houtkoop-Steenstra, N. C. Schaeffer \& J. van der Zouwen (Eds.), Standardization 
and tacit knowledge. Interaction and practice in the survey interview (pp. 151-61). New York: John Wiley.

Speer, S.A. (2002a). "Natural” and "contrived" data: A sustainable distinction?' Discourse Studies, 4, 511-25.

Speer, S. A. (2002b). Transcending the "natural" / "contrived" distinction: A rejoinder to ten Have, Lynch and Potter. Discourse Studies, 4, 543-48.

Speer, S.A. (2002c). What can conversation analysis contribute to feminist methodology? Putting reflexivity into practice. Discourse \& Society, 13, 783-803.

Speer, S. A. (2013). Talking about sex with patients in the Gender Identity Clinic: Implications for training and practice. Health. DOI 10.1177/1363459312472085

Speer, S. A., \& Hutchby, I. (2003a). From ethics to analytics: Aspects of participants' orientations to the presence and relevance of recording devices. Sociology, 39, 31537.

Speer, S. A. \& Hutchby, I. (2003b). Methodology needs analytics: A rejoinder to Martyn Hammersley. Sociology, 39, 335-59.

Speer, S. A. and Stokoe, E. (2012). Ethics in action: Consent-gaining interactions and implications for research practice. British Journal of Social Psychology. DOI $\underline{10.1111 / \text { bjso. } 12009}$

Stokoe, E. (2009). "For the benefit of the tape": Formulating embodied conduct in designedly uni-modal recorded police-suspect interrogations. Journal of Pragmatics, 41, 18871904.

Stokoe, E. (2013). The (in)authenticity of simulated talk: Comparing role-played and actual conversation and the implications for communication training. Research on Language and Social Interaction, 46 (2), 1-21. 
Wade, J., Donovan J. L., Lane J. A., Neal, D. E., \& Hamdy, F. C. (2009). "It's not just what you say, it's also how you say it: Opening the "black box" of informed consent appointments in randomised controlled trials. Social Science \& Medicine, 68, 2018 28. 